This item was submitted to Loughborough's Research Repository by the author.

Items in Figshare are protected by copyright, with all rights reserved, unless otherwise indicated.

\title{
Parties, advocacy and activism: Interrogating community and class in digital queer India
}

\section{PLEASE CITE THE PUBLISHED VERSION}

http://dx.doi.org/10.1057/9781137383556_19

\section{PUBLISHER}

Palgrave Macmillan

\section{VERSION}

AM (Accepted Manuscript)

\section{PUBLISHER STATEMENT}

This work is made available according to the conditions of the Creative Commons Attribution-NonCommercialNoDerivatives 4.0 International (CC BY-NC-ND 4.0) licence. Full details of this licence are available at: https://creativecommons.org/licenses/by-nc-nd/4.0/

\section{LICENCE}

CC BY-NC-ND 4.0

\section{REPOSITORY RECORD}

Dasgupta, Rohit K.. 2019. "Parties, Advocacy and Activism: Interrogating Community and Class in Digital Queer India”. figshare. https://hdl.handle.net/2134/25210. 


\section{Parties, Advocacy and Activism: Interrogating Community and Class in Digital Queer India}

Rohit K. Dasgupta

New media and the internet have had a significant impact on the queer community in India. From cyber-activism challenging media and political discourses on queer identity to providing a social space for interaction and dialogue (Roy 2003; Shahani 2008), they have been instrumental in the growth of the 'marginalized' queer community in the country. This chapter draws on and develops research on online queer communities (Campbell 2004; Mowlabocus 2010) and examines a Facebook group for queer individuals in Kolkata, India as a 'community'. My intention in this chapter is to see how a sense of community is created and expressed and even critiqued within this specific group. Spaces such as this not only challenge institutional normativity but also offer an alternative to the NGO-led queer support model so prevalent in India. Using a Facebook group called Pink Kolkata Parties (PKP) as a case study, this chapter will be looking at the intersection and tensions between class, gender and sexuality and how that inflects our understanding of community and more largely identity. The chapter will specifically explore how the notions of a queer youth community in cyberspace circulate and the mechanisms of inclusion/exclusion that govern the dialogue and interaction within this space.

With regard to the research methodology, the names have been changed to protect the identity of the participants, except when they are public figures. Hence, while the identities of queer activists Pawan Dhall and Anindya Hajra are present, contributors 'Rudranil', 'Sushovan', 'Amit', 'Carl', 'Richard', 'Raj' and 'Romit' are anonymous identities. 


\section{Whose community is it anyway?}

A prominent queer activist, Pawan Dhall, recounts his early days of trying to build a queer community in Kolkata:

In the early days it was very difficult to meet other people in Kolkata. The Gaybombay group in Bombay were very helpful in setting up eforums for the other cities and very soon we had a Gay Calcutta eforum. This meant we could connect with others all over India. In the beginning, there were only around five members and there were mostly arguments and fights, nothing concrete ever came out. I was often frustrated at the lack of dialogue in these spaces and left the forums many times. However within a very short space of time, we were suddenly inundated with members and it also helped that service users could remain anonymous or keep their details confidential

(Dhall 2013)

Queer online spaces in India can be mapped as this vast terrain of digital sites; these include gay blogs (Gajjala and Mitra 2008), listservs which are created specifically for queer people (Roy 2003) and social networking sites such as Planetromeo (formerly Guys4Men) and Facebook. The primary aim of using such sites, as Dhall's comment articulates, was to establish connections with others offering a way of breaking into a world that was under constant threat from the societal hegemonic heteronormativity. Queer spaces in Kolkata are often transitory spaces that are vulnerable to change and are at constant risk of ceasing to exist.

Today sexuality and gender is a defining feature of identity assertion and community formations. Queer communities are shaped by the multiple interactions within the various contexts of nationality, class, religion and race. Henderson (2013) in her cultural critique and exploration of race and class in the United States, argues that social class makes a significant difference to queer subjectivity and representation. She contends that we 'cannot see queer cultures clearly enough when we ignore class, nor can we see contemporary class outside the production of sexual difference' (2013, p. 1). Pawan Dhall relates the inconsistency in queer political alliances when back in 2000 he first realized most gay men on the Calcutta e-forums were quite 'trans-phobic' and advised him to 'stay away from these low class people' (Dhall 2013). What this reveals is interesting because class location and identification are vital in South Asia (Herring and Agarwala 2008). It illustrates how class determines 
choice relative to the structure of freedom and compulsion, and the opportunity for agency. Within the Indian queer community it is vital to look at class within the discourse of inclusion and exclusion. Sexual identity politics has not replaced class politics; rather it is embedded within structures of constraints and opportunities.

For queer individuals, the advent of transnational media connections across diverse nations offers new scope for sexual identification. Steven Vertovec (2010) tells us 'cheap telephone calls, faxes, email and frequent modes of travel have allowed for continuous and real time communication' (p. 15). Christopher Pullen (2102) argues that this has allowed 'the discursive potential of an imagined gay or LGBT community [to] seem vividly real, enabling coalescence, interactivity and identity formation' (p. 6). Consequently I would argue this 'imagined' community is enabled not so much by a shared commonality (it is in fact quite fragmented) but rather it is about disparate queer community groups which have united and sustained a common dialogue to challenge mainstream oppression led by dominant heteronormative worlds (Bhan and Narrain 2005).

Tracing queer virtual communities in Kolkata is thus not only about studying the text available on the websites themselves; it is equally important to recover those voices that are subdued and have no place within the forums. More often than not, these individuals have been rendered voiceless on the basis of their class and linguistic affiliation, thus making it imperative to read into what has not been said and interrogate the textual site to reclaim the narratives and dynamics (Spivak 1988) that are buried or not given a space to express. In my attempt to recover the queer subaltern youth who are absent and silenced on the site, I have used empirical data from interviews with a range of participants and contextualized and placed them within the context of absence.

\section{Pink Kolkata Party}

PKP is an online/offline group comprising a Facebook group and physical events in the city of Kolkata, which was formed to cater to the socializing needs of the queer populace in the city. It started off as a Facebook group to reach out to the queer community promoting the idea of a regular physical meeting. A Wednesday regular date at a popular coffee shop in central Kolkata was decided on before the administrators and some of the group members also decided to follow this up with regular Pink Party events at popular mainstream clubs. The 
idea was to influence the mainstream urban space with queer presence instead of creating separate queer spaces. Oswin (2008) identifies queer space as occupied either by self-identified queer people or those who are defying and contesting power and heteronormativity. These spaces are highly segmented and are under constant threat of accessibility. Virtual spaces in theory help circumvent some of these threats. In recent years this has played a very important role in the growth of queer consciousness and mobilizing towards queer rights (Shahani 2008).

Many researchers have argued that the growth of computers and computer-mediated communication has been crucial to the development of queer communities (Berry et al. 2003; Campbell 2004; Mowlabocus 2010). The increase in queer visibility and queer awareness can be attributed in large part to the growth of the internet and groups such as PKP, PlanetRomeo and so on. Berry et al. (2003, p. 1) have argued that the recent emergence of gay and lesbian communities in Asia and its diaspora is intimately linked to the development of information technology in the region'.

The first 'party' that emerged from the discussions on the online group was held at an upmarket five star club in the city called Rocky at the Garden Hotel. The move was seen as highly successful because for the first time a mainstream club with restrictive policies allowed a queer party to take place within its premises. Despite the promise of the party, great consternation was created when many revellers who had turned up were turned away by the club management for 'dressing inappropriately' ('Amit' 2013), suggesting that the management of the club were uncomfortable with the idea of the event. There was an outcry over this prejudiced behaviour of the club management and the members and administrators of PKP took to the Facebook group to vent and discuss their grievance.

Anindya Hajra, a prominent queer activist and one of the administrators of the group, vented:

It was a humiliating and emotionally debilitating experience for many who arrived early to be denied entry at the gates, despite being 'appropriately' dressed without citing any reason whatsoever - and in a case of clearly homophobic/ transphobic screening allowing others over members of this group the right to entry.

(Hajra 2011)

I recount this occasion to think about the politics of recognition within everyday life that marks this event. Firstly there was the club's hostile 
recognition of the group member's dissident sexual and gender (trans) identity, which was considered as perverse by their standard. Secondly there was a more insidious issue, related to reading class within valuations of identity. I have conflated sexual identity with class power here to illustrate that class is linked intrinsically to sexual identity and knowledge, and recognition of oneself does not automatically offer illumination of the other. Class signification is imperative in constructing the queer male in Kolkata, India. While the club had decided to relax its door policies for the queer 'community' it was still regulating the class dynamics of the group.

Henderson (2013, p. 71) states that 'recognition takes many forms, though some categories of social difference like sexuality have been more amenable to a positive politics of recognition, while others like class have been less so'. This is certainly true for this incident, because while a simplistic reading of the incident would bring up sexual identification as the reason for exclusion, a closer reading would reveal that there was a class-based bias, as the following sections will demonstrate. The management was aware that a queer party was scheduled to arrive for the evening, and even allowed some of the patrons entry, while denying others. It is interesting how this debate generated different responses in varying contexts from members within the community belonging to different classes. 'Rudranil', an upper middle class fashion designer ${ }^{1}$ writing about this incident on the PKP group notes:

Well iv been publically out for many years now, and i have never faced any prejudiced behavior from any1 at The Garden, ihv made out wth guys on the floor in Rocky, Sutra, Regis\& TRC infront of The Garden management even before the decriminalization of the 377 act, yet The Garden has been very gay friendly \& nice to me ... . It is just unfortunate to find out that few PINK members were mistreated at The Garden!!

(July 21, 2011)

The point made by 'Rudranil' is important because he articulates that the issue had nothing to do with sexuality. On previous occasions when he had visited the various clubs of the hotel (Rocky, Sutra, Regis and $\mathrm{TRC}$ ), he had never been discriminated against. In fact, to vouch for the queer friendliness of the administration of the hotel, he even recounts 'making out with guys on the floor' without being asked to leave. What he demonstrates in this comment is the non-recognition of the power of class dynamics and the social class of those who were turned away. Issues 
of class and privileged identification reveal problematic contexts, in estimating the real-life situation of outsiders and those from less privileged classes. It's possible that those from different classes do not necessarily understand each other's contexts.

McDermott (2011, p. 64) has argued that 'social class [is] a major axis of power which positions LGBT people unequally and unjustly'. This incident thus opens up a conversation about social class and sexuality that exposes the layered experience of class difference within the PKP community.

\section{Class identification and the fractured community}

McDermott (2011, p. 66) has argued that queer theories are based upon a politics of visibility by which dominated groups unite through their signs of oppression and demand recognition as an oppressed community. However, she notes, referencing the work of Clark (1991) that 'these 'classless' sexual identity politics are compounded by cultural representations of lesbian and gay men which are predominantly, middle class, affluent and white'.

The Pink Party debacle and its subsequent debate on the PKP page highlights the difficulties that subaltern queer voices face from within and outside the community. It was surprising that there were only two people who were denied entry who were actively discussing this on the thread. Most of the others were silent or did not respond by participating in this on-going dialogue. However, following Spivak (1988), I would argue that the issue concerns not only the lack of opportunity to speak and be heard (silencing), but the fact that there were queer voices on the PKP site arguing that the club's policy as acceptable renders oppositional statements as useless. The subaltern's speech, as Spivak has argued previously, is only mediated and represented but never fully replicated. 'Amit' was one of the revellers who were turned away at the gate. $\mathrm{He}$ narrated his version of the story to me:

I went to the club with two other friends. We had never ever been to this hotel before, but because this was a community party we pooled together money (It was 850 rupees per person) to attend. But when we went to the gate, the manager; a woman looked at us up and down and told us rudely that we cannot go in. When we asked why, she said it was 'couples only'; which was obviously a lie because I could see other single men entering. I did not want to 
argue as I was embarrassed and ashamed. We went away feeling very humiliated.

('Amit' 2013)

On being asked why he did not share his story on the group thread he said he felt this incident reflected on his own (class) background, as he was not able to live up to the class identity of the other group members who were able to access the venue. He felt comfortable not making his class identification public to others. His statement highlights his recognition of the apparent discomfort in the revelation of his class background and the vulnerability of public exposure (Henderson 2013, p. 79). Henderson (2013, p. 88) contends that cultural systems of class attribution are always partial. They signify a cultural capital as well as other attributes such as middle class modesty or a self-conscious entrance into another class.

\section{When race meets class}

At this point I would like to relate a second incident relative to the Pink Party forum more than a year after the incident at the Garden. By recalling this incident I would like to focus on the intersection between class, race and queer subjectivity in the city and how the different voices merged and ranged on the online forum. Not only did it expose the fractures within the group a year later but it also helps critique the community discourse. This time, a party was held at a private farmhouse, owned by a white expatriate of Canadian origin living in Kolkata, where group members were asked to pay a cover charge for entry. What should have supposedly been a safe party with no issues around accessibility took a turn for the worse, when the next day details of classism and racism were levelled against the organizers and the host himself started to appear on the Facebook group.

Some of the group members alleged that they were thrown out of the party late at night while they were drunk, and in a somewhat vulnerable situation. They claimed that while certain members were allowed to stay the night, many of the others were unceremoniously asked to leave the property immediately after the advertised time. For a long time none of the organizers or the hosts made any comment until 'Carl', the expat host decided to intervene and defend PKP and the Party:

Seriously Rony and others that find it necessary to critique the PKP events. You really have to understand that PKP is not a profesional 
event company, hotel or caterer. It is organized by private individuals who donate time and energy towards it. I know exactly what your options are in this city- cheap smoke filled dark and dingy bars.

('Carl', October 24, 2012)

While the comment by 'Carl' is critical and potentially objectionable, it illuminates what he considers to be the options for the queer men in the city. His comments highlight how income, wealth and class privilege frame the opportunities for queer youth relative to entertainment in the city. They do not have the privilege of accessing other venues and so their criticism regarding this event was unacceptable to him. He was not alone in his defence. Another group member, 'Richard', who also attended the party, attested: 'id say be grateful! and stop whining! why does everyone whine here!!???' (October 24, 2012).

However, in exploring class type structures, queer difference and queer specificity, Henderson $(2013$, p. 57) claims that any mode of queer class analysis foregrounds patterns of 'comportment, familialism and legitimate acquisition of the good life in the commercial ratification of queerness'. Research shows (McDermott 2011) that social class is implicated in the ways in which LGBT people choose to identify themselves and the social choices they decide to make. In this instance it reveals not just the motivations of 'Carl' (who decided to throw some group members out) but also of those who decided to raise their voice against this perceived injustice. 'Sushovan', one of the group members, also protested against the elitism being shown by some of the members in the forum. In reply to a comment by 'Richard',

dont come looking for caviar with an entry fee of Rs. 1100. Next time $\mathrm{u}$ organise a party and make sure caviar is on the menu and id like some wine with it

('Richard', October 24, 2012)

he writes:

This comment by 'Richard' is absolutely in the league of 'if they dont have bread...' not that I ever had a very high opinion of PKP being a socially responsible forum (its after all populated by the likes of XXX) but this is outrageously classist, elitist and condescending comment. I demand an apology!!! 
The comment made by 'Sushovan' sums up the essence of the debate by bluntly critiquing the PKP administration for this debacle. Interestingly enough, 'Richard' replies to this comment asking 'Sushovan' 'who are you?' (October 24, 2012) to which another group member replied, 'why will social profiling him help you better on how to address your comments towards him?' ('Romit', October 24, 2012).

My attempt here is not to discredit the PKP group but rather to critique and challenge the elitism of its members, which has not been addressed so far. Agreeing with Henderson's critique that 'queer class life has nowhere to go and nothing to do except to live with the limits dominance imposes, learning class rules from the cultural ether ...' (2013, p. 59), I want to use this event as an instance where the silenced voices of the group actually spoke up, a marked difference since the last event at the Garden. While the administrators ultimately did try to openly engage with the group members in explaining (albeit defending 'Carl') the events of the previous night, it publicly opened up the deeply divided queer community on its online pages, something that had happened only intermittently. 'Sushovan' also used the event to critique the racism (again along class lines) of the host. In reply to the moderator he asked:

The fact that this [rich] white man chucked so many brown skinned working/middle class boys out by their neck, how come that is not being addressed?)

('Sushovan', October 24, 2012) ${ }^{2}$

Although this question remained unanswered, it foregrounds some of the issues and disjunctions around class within the queer community which in some senses were heighted by a failure to engage.

\section{Conclusion}

PKP offers an alternative space for queer entertainment and queer intermingling in the city. While one of the primary implicit aims of the group when it was formed was to help in creating and sustaining a community, it has not been that successful. When I interviewed some group members they all described it as a community space and many referred to themselves as 'pinkies' (members of PKP). In an interview conducted with 'Raj', he described PKP as 'a highway stop where all the gays of Kolkata meet at some time or the other'. These are 'people you may know or will get to know from the forums'. The group's 
open boundaries further encourage people from around the globe, especially those with a connection to Kolkata, to come together. While the name ' $\mathrm{PKP}$ ' indicates a geographical specificity, I would argue that the space addresses a potential global queer community, challenging border divides and opening up a global interconnectedness. Pullen (2012) has argued that such transnational identity challenges the notion of a Western-centric LGBT mode. He writes: 'this sense of a new shared imagination, enabled by transnational potential challenges the notion of a Western queer subjectivity' (2012, p. 6). Mowlabocus (2010, p. 87) in his exploration of the sociality of online queer spaces has noted that 'websites such as Gaydar have provided important resources to combat the isolation and marginalization that growing up gay in a straight world often engenders'. The space offered by groups such as PKP affirms queer existence and queer expression by emphasizing and centralizing the participant's sexuality through discussions around queer issues and organizing queer entertainment options. However, such affirmation comes at a cost, as demonstrated above. Alexander (2002, p. 90) comments that queer online spaces impose various forms of boundaries and unfortunate bigotries, 'a biting reminder that in-group membership status within the gay male community often comes at a certain price, extracted on the body of those seeking inclusion'.

The people that I have quoted and those who spoke without hesitation to me 'stand [ ... ] as an invitation or beacon, a brightness on the social horizon through which painful, sometimes shameful, experiences and feelings are pressed into recognition' (Henderson 2013, p. 97). Their collective narratives act as a redemptive device, dissenting from 'accepted narratives' and voicing contrary opinions. The public personification relative to class subjectivity on the forum allows them to be in possession of their own condition and position and also critique dominant groupings. As a significant minority, they can be awarded a positive value as they hold the right to dissent (Appadurai 2006). Appadurai contends that in the liberal imagination, large majorities lose their rationality as they are shaped by outside forces such as the state or other dominant voices. The same can be seen with the dominant queer voices. Thus voices such as Anindya Hajra, 'Sushovan' and 'Amit', transcend the dominant, offering diverse opinions and approaches.

I would like to argue that social exclusion is not just limited to a disparity in access to the internet, but is also about being able to productively engage in a conversation with others without being subject to class inequalities concerning identification. PKP, through its 'boundary practice' - an exercise that assists the administration of boundaries 
an identities between different social worlds inhabited at home, school family and social circles (Campbell 2004) - has the potential to allow users to engage in meaningful dialogue on issues central to themselves and the city.

PKP occupies a unique position within the queer imagination of the city. By situating itself within a mainstream site such as Facebook it appropriates a heteronormative spaces and queers it. It does not work in the same way as sites like Planet Romeo of Gaydar function rather it offers structure and opportunities for agency in the manner of a cybercottage (Mowlabocus 2010). Its closed nature renders it almost anonymous; however, by working through a referral system where members can add their friends it manages to reach out to its target audience, offering opportunities for engagement.

Class has always been a contentious issue and this is specifically apparent within the queer community, where the mainstream media representations of queer people within the narrow stratum of the white, the male and the affluent offer little depth of equality (Demory and Pullen 2013). As Demory and Pullen (2013, p. 6) have pointed out, representation politics of non-normative sexualities has always positioned between a certain degree of tolerance and a superficial tokenism of the alternative. As pointed out by Kuntsman and Miyake (2008), Boyce (2006) and Henderson (2013), queerness continues to be a restricted identity category, especially for those who are economically underprivileged who do not have access to adequate resources. This is exacerbated when media representations of queer people are skewed towards a white, high-earning class, making it even more difficult for others to actively engage in a process of self definition with limited forms of representation to associate with. Spaces such as PKP and KRPF (Kolkata Rainbow Pride Walk) have in recent years opened up a valuable space for dialogue, actively engaging questioning individuals to ask questions and meet others, and fostering acceptance while, however, also implicating and creating other discriminatory structures for some.

PKP offers a cosmopolitan vision (Beck 2008, p. 3) which reveals 'a reflexive awareness of ambivalences ... blurring of differentiations'. A universal community is not the solution but rather the subversive potential of the PKP space in opening up a dialogue between the unheard voices and the dominant ones is crucial for human rights discourses as well as national queer politics. As Shahani (2008) has explicated, mobility within the queer community is a privilege only a few can afford and for those bodies which cannot travel, a space like PKP opens up a space for social gathering (both online and offline). 
PKP exists within a diverse constitution of queer identities in Kolkata. It has been an instrumental figure in the last three years in the queer sociality and entertainment barometer of the city. As an online group it is much more active than its physical constitution, which may be seen to be limited, evident in the fact that the Wednesday evening coffee meetings have more or less stopped. While the online presence has been an important ground for disparate voices to debate and challenge the myth of a queer community, it has failed to address the diverse range of class and economic issues relative to its members. Like many other online groups, the PKP community is characterized by certain progressive ideals towards open dialogue and creating queer spaces in the city but at the same time it fails to engage, addressing issues of diversity among the different class and economic backgrounds that it purports to represent.

\section{Notes}

1. This is by virtue of his economic and social position in Kolkata, India. Class structures in India are quite complicated and cover not only issues of economic power but also social standing in the community. See Herring and Agarwala (2008) for a range of perspectives.

2. This is a translation of the original text in Bengali 'shaheb je etogulo brown skin middle class bachha chhele ke nijer bungalow theke ghaar dhaaka diye ber kore dilo, sheta niye to ekta kothao shone gelona?'

\section{References}

Appadurai, A. 2006. Fear of Small Numbers. An Essay on the Geography of Anger. Durham: Duke UP.

Beck, U. 2008. Cosmopolitan Vision. Cambridge: Polity Press.

Berry, C., Martin, F. and Yue, A. 2003. Introduction. In C. Berry et al. eds. Mobile Cultures: New Media in Queer Asia. Durham: Duke UP, pp. 1-19.

Bhan, G. and Narrain, A. 2005. Because I Have a Voice: Queer Politics in India. New Delhi: Yoda.

Boyce, P. 2006. Moral Ambivalence and Irregular Practices: Contextualizing Maleto-Male Sexualities in Calcutta/India. Feminist Review, 83(1), pp. 79-98.

Campbell, J.E. 2004. Getting It On Online: Cyberspace, Gay Male Sexuality, and Embodied Identity. New York: Haworth Press.

Clarke, D. 1991. Commodity lesbianism. Camera Obscura 25/26, pp. 181-201.

Demory, P. and Pullen, C., eds. 2013. Queer Love in Film and Television. Basingstoke: Palgrave.

Dhall, P. 2013. Personal Communication, July 11, 2013.

Gajjala, R. and Mitra, R. 2008. Queer Blogging in Indian Digital Diasporas: A Dialogic Encounter. Journal of Communication Inquiry, 32, pp. 400-423.

Hajra, A. 2011. Personal Communication, July 21, 2011 
Henderson, L. 2013. Love and Money: Queers, Class and Cultural Production. New York: New York UP.

Herring, R.J. and Agarwala, R. 2008. Whatever Happened to Class? Reflections from South Asia. London: Routledge.

Kuntsman, A. and Miyake, E. 2008. Out of Place: Interrogating Silences in Queerness/ Raciality. New York: Raw Nerve.

McDermott, E. 2011. The World Some Have Won: Sexuality, Class and Inequality. Sexualities, 14(1), pp. 63-78.

Mowlabocus, S. 2010. Gaydar Culture: Gay Men, Technology and Embodiment in Digital Age. Aldershot: Ashgate.

Oswin, N. 2008. Critical Geographies and the Uses of Sexuality: Deconstructing Queer Space. Progressive Human Geography, 32(1), pp. 89-103.

Pullen, C. 2012. Introduction. In C. Pullen, ed. LGBT Transnational Identity and the Media. Basingstoke: Palgrave, pp. 1-20.

Roy, S. 1995. From Khush List to Gay Bombay: Virtual Webs of Real People. In C. Berry et al. eds. Mobile Cultures: New Media in Queer Asia. Durham: Duke UP, pp. 180-199.

Shahani, P. 2008. GayBombay: Globalisation, Love and Belonging in Contemporary India. New Delhi: Sage.

Spivak, G. 1988. Can the Subaltern Speak? In C. Nelson and L. Grossberg, eds. Marxism and the Interpretation of Culture. Urbana: Illinois UP, pp. 271-313.

Vertovec, S. 2010. Transnationalism. Abingdon: Routledge. 